\title{
Noninvasive assessment and monitoring of the pulmonary circulation
}

\author{
A. Vonk-Noordegraaf*, S.A. van Wolferen*, J.T. Marcus", A. Boonstra*, \\ P.E. Postmus*, J.W.L. Peeters ${ }^{\top}$ and A.J. Peacock ${ }^{+}$
}

ABSTRACT: In pulmonary vascular disease, changes in the pulmonary vascular bed will lead to altered pulmonary haemodynamics. This review describes the application of several physiological principles to measure these changes noninvasively by means of novel techniques.

Flow characteristics of blood through the pulmonary vascular bed alter in pulmonary vascular disease. Recent developments in magnetic resonance imaging and computed tomography make it possible to visualise and quantify these abnormal flow patterns. Information regarding pulmonary perfusion can also be obtained by measuring the electrical impedance changes in the lung by electrical impedance tomography. A more indirect approach to measure the pulmonary blood flow is the measurement of the absorption of acetylene, a perfusion limited gas. Information on the pulmonary vascular bed can also be obtained by the measurement of exhaled products of the pulmonary vascular endothelium, such as nitric oxide.

Although all the techniques described offer new ways to diagnose or monitor pulmonary vascular disease, clinical data on these techniques are limited. Further improvement and evaluation of the clinical value of these techniques are therefore obligatory before they can be used in clinical practice.

KEYWORDS: Acetylene diffusion, computed tomography, electrical impedance tomography, magnetic resonance imaging, perfusion, pulmonary hypertension

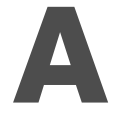

low arterial pressure and peripheral vascular resistance (PVR) are characteristics of the pulmonary circulation. Both the low pressure and resistance are a result of the specialised function and anatomy of the pulmonary vascular bed. The pulmonary vascular bed consists of highly distensible vessels, which are able to accommodate large increases in blood volume, as in exercise, while retaining a low pressure by distension and recruitment of the pulmonary microvascular bed [1]. In diseases affecting the pulmonary vasculature, loss of the pulmonary vasculature and obstructive pathological changes of the pulmonary vasculature, such as thrombotic lesions, medial hypertrophy and intimal fibrosis, leads to an increased PVR and pulmonary artery pressure (PAP). However, due to the distensibility and the large recruitment capacity of the pulmonary vascular bed, normal resting PAP will rise relatively late in the course of the disease, when up to $70 \%$ of the bed is already obstructed. For the most commonly used noninvasive technique to diagnose pulmonary vascular disease, Doppler echocardiography, an increased PAP is a prerequisite to diagnose pulmonary vascular disease [2]. Assessing pulmonary vascular disease by means of estimating $\mathrm{PAP}$ in this way requires extensive pulmonary vascular damage before the diagnosis can be made. Furthermore, PAP appears a rather insensitive variable to monitor the course of the disease [3-5]. For this reason more sensitive

Previous articles in this series: No. 1: Man WD-C, Moxham J, Polkey MI. Magnetic stimulation for the measurement of respiratory and skeletal muscle function. Eur Respir J 2004; 24: 846-860. No. 2: Farré R, Montserrat JM, Navajas D. Noninvasive monitoring of respiratory mechanics during sleep. Eur Respir J 2004; 24: 1052-1060. No. 3: Calverley PMA, Koulouris NG. Flow limitation and dynamic hyperinflation: key concepts in modern respiratory physiology. Eur Respir J 2004; 25: 186-199. No. 4: Scano G, Stendardi L, Grazzini M. Understanding dyspnoea by its language. Eur Respir J 2005; 25: 380-385.

\section{AFFILIATIONS}

*Dept of Pulmonology,

\#Dept of Physics and Medical

Technology, and

"Dept of Radiology, VU University

Medical Center, Amsterdam, The Netherlands.

${ }^{+}$Scottish Pulmonary Vascular Unit, Western Infirmary, Glasgow, UK

CORRESPONDENCE

A. Vonk-Noordegraaf Dept of Pulmonology VU University Medical Center De Boelelaan 1117 1081 HV Amsterdam The Netherlands Fax: 3120444328 E-mail: a.vonk@Vumc.nl

Received:

October 252004

Accepted after revision:

December 282004 
noninvasive techniques for assessing the pulmonary vascular bed will not only be desirable to diagnose early stages of pulmonary vascular disease, but might also provide a better tool to monitor the effects of therapy. This review aims to present novel ways to noninvasively measure the characteristics of the pulmonary circulation.

\section{MEASURING PULMONARY VASCULAR FUNCTION}

Since the pulmonary microvascular bed cannot be visualised noninvasively, information about its function can only be obtained indirectly. Several approaches to measure the characteristics of the pulmonary vascular bed have been developed in recent years. The most direct approach is the measurement of pulmonary perfusion by the passage of contrast fluid through the lungs. Recent advances in magnetic resonance imaging (MRI) and computed tomography (CT) make it possible to study the dynamics of pulmonary perfusion of the small pulmonary vessels in real time. An alternative approach is to measure the change in electrical impedance during the cardiac cycle, since electrical impedance changes are proportional to blood volume changes. Based on this principle, electrical impedance tomography (EIT) has been developed, making it possible to visualise and measure the pulmonary blood volume changes during the cardiac cycle. A more physiological approach is the estimation of capillary blood flow from the absorption of acetylene, a perfusion limited gas. Finally, the production of endothelial factors, such as nitric oxide (NO), can be analysed in the exhaled air as an indicator of pulmonary endothelial function. Since the focus of this review is the pulmonary vascular bed itself, other promising techniques directed at the right heart will not be discussed.

\section{CONTRAST-ENHANCED MAGNETIC RESONANCE IMAGING}

Local narrowing of arteries or arterioles, as in pulmonary arterial hypertension (PAH), will lead to local higher resistance and thus to slower perfusion in the regions supplied by those arteries. For this reason, measuring the characteristics of the pulmonary vascular bed by means of pulmonary perfusion requires a technique with a good spatial distribution and temporal resolution. Contrast enhanced MRI (ceMRI) is both fast and 3-dimensional (3D) by nature: in any 2-dimensional (2D) image plane a functional $2 \mathrm{D}$ perfusion map can be acquired in successive time intervals of $\sim 150 \mathrm{~ms}$ [6]. This dynamic 2D ceMRI has proven its value in characterising malignant nodules by fast signal increase after contrast injection [7]. Alternatively, a full 3D coverage of the lungs (MR angiogram) can be acquired in $3 \mathrm{~s}$ time steps or even faster [8, 9]. For this procedure, a Gadolineum-based MRI contrast agent is administered by intravenous bolus injection to shorten the longitudinal relaxation time in the surrounding hydrogen nuclei. As an option, the MRI acquisition is triggered by the ECG $\mathrm{R}$ wave in order to measure the subsequent perfusion maps in the same phase of the cardiac cycle. The patient is instructed to hold their breath during acquisition. The MRI perfusion image planes can be selected in a position and orientation that is adapted to the clinical or research question. For dynamic analysis, the arterial input function must be known and thus either the right ventricle (RV) or the main pulmonary artery should be included in the perfusion image. A cardiac short-axis image plane has the advantage that both the pulmonary input function (contrast arrival in the RV), as well as the pulmonary output function (arrival in the left ventricle), can be derived from the same acquisition (fig. 1). For optimal coverage of all regions of the lungs, coronal planes are preferred where the main pulmonary artery is included in one of the image planes for obtaining the input function (fig. 2). As yet, few clinical studies have been performed that exploit the data from dynamic pulmonary perfusion. Until now, time-resolved 3D MRI perfusion has been applied to measure the impact of pulmonary vein stenosis after radio frequency ablation for atrial fibrillation; perfusion deficits were reliably demonstrated [8]. Dynamic 3D MRI perfusion was also applied by FINK et al. [10] and OHNO et al. [9] to show the wedge shaped deficits in pulmonary embolism and the delayed perfusion in PAH. Figure 3 demonstrates the regional pulmonary perfusion time curves in two patients with mild and moderate pulmonary hypertension, respectively. Subjects were lying supine in a 1.5 Tesla whole-body "Sonata" MRI system (Siemens Medical Solutions, Erlangen, Germany). Regions of interest for perfusion analysis $(5 \mathrm{~cm} \times \mathrm{cm}$ area) were drawn in the anterior and posterior lung regions. One perfusion per heart beat was analysed, starting at contrast arrival in the RV,
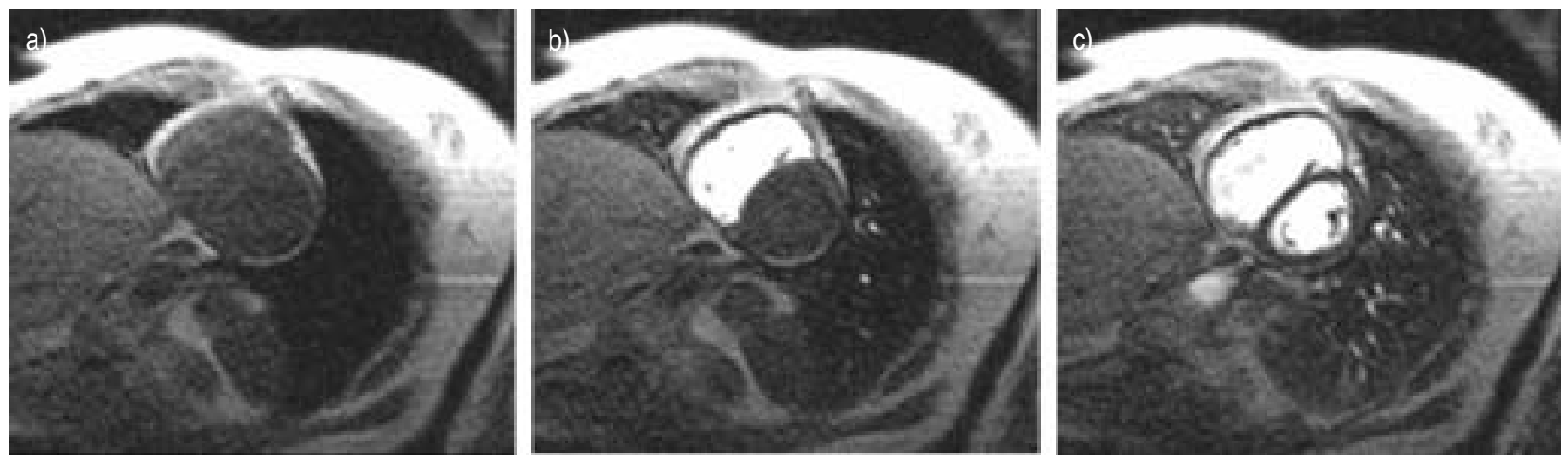

FIGURE 1. Magnetic resonance imaging perfusion example images: baseline (a), contrast arrival in right ventricle (b), and contrast arrival in the lungs (c). Field of view $290 \times 380 \mathrm{~mm}$, pixel size $2.8 \times 2 \times 8 \mathrm{~mm}$, triggered by the ECG R wave, one image per cardiac cycle, trigger delay $365 \mathrm{~ms}$. In the anterior and posterior parts of the lung, regions of $5 \mathrm{~cm}^{2}$ were delineated for dynamic perfusion analysis. 

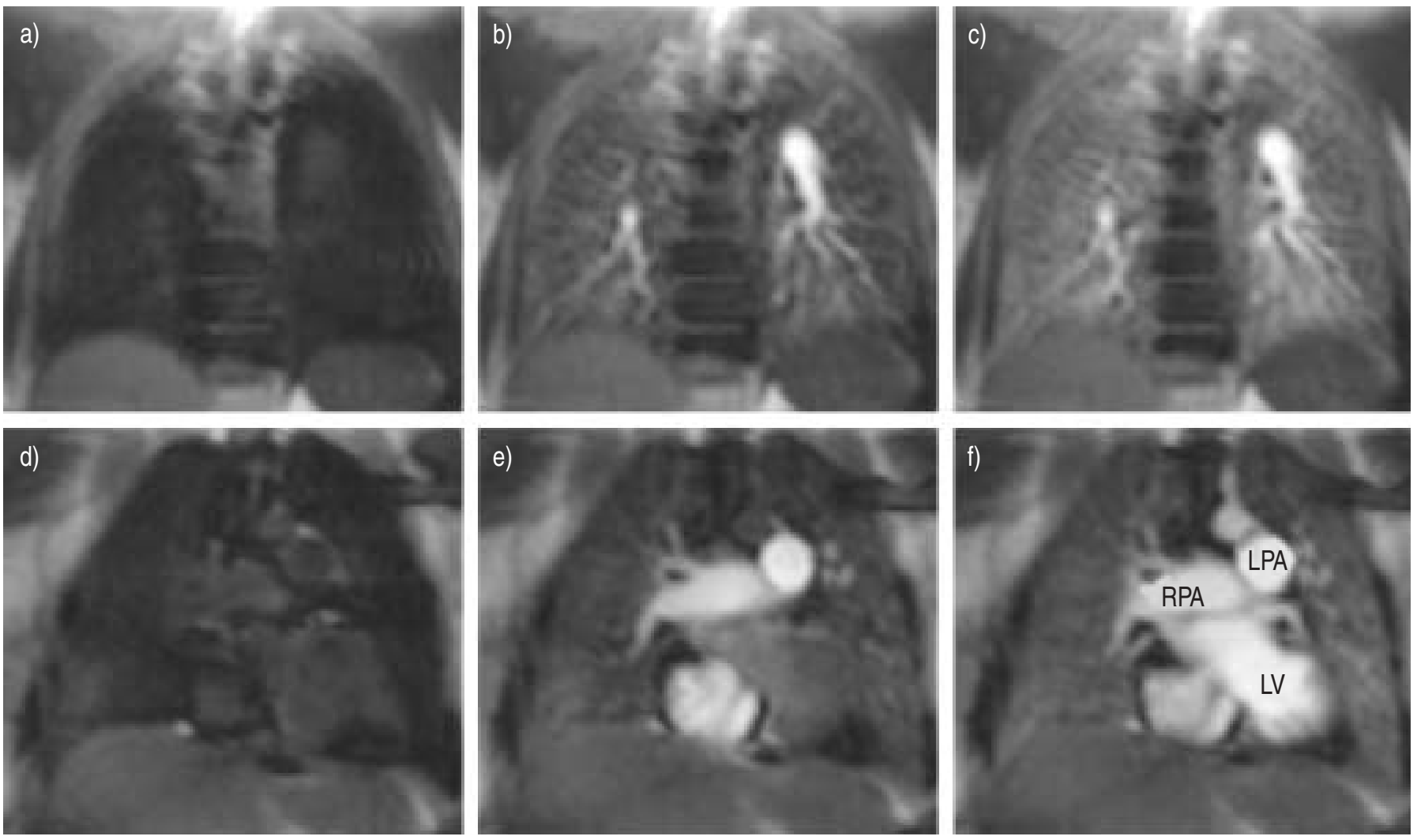

FIGURE 2. Magnetic resonance imaging perfusion images in a pulmonary hypertension patient, in two separate coronal planes at $t=0 \mathrm{~s}$ before contrast arrival (a, $d)$, at $\mathrm{t}=6 \mathrm{~s}(\mathrm{~b}, \mathrm{e})$ and at $\mathrm{t}=8.7 \mathrm{~s}(\mathrm{c}, \mathrm{f})$. Contrast arrival at $\mathrm{t}=6 \mathrm{~s}$ is evident from the signal increase in the right ventricle (e). At $8.7 \mathrm{~s}$, the contrast has reached its peak level in the lungs, and also becomes visible in the left ventricle (f). Acquisition parameters: voxel size $3.5 \times 2.7 \times 10 \mathrm{~mm}$, slice distance $40 \mathrm{~mm}$, single-shot steady state free precession pulse sequence with one image in every $150 \mathrm{~ms}$. In this example, a $90^{\circ}$ saturation pulse was applied, with inversion time of $90 \mathrm{~ms}$. LV: left ventricle; LPA: left pulmonary artery; RPA: right pulmonary artery.

through 20 subsequent heart beats. Perfusion curves from the mild PAH patient showed that the posterior and anterior lung regions show peak contrast enhancement at the 5th and 8th heart beat after injection, respectively, with evident earlier enhancement in the posterior region. At the 20th heart beat the contrast is largely washed out. Similar curves from the patient with moderate PAH showed that peak enhancement is now only at the 14 th and 17 th heart beat, with no evident difference between anterior and posterior lung regions. At the 20th heart beat there is no sign of wash-out. From these curves it is demonstrated that an increase in the PVR leads to a slower passage of the contrast fluid through the peripheral parts of the lung and a regional distribution no longer determined by gravity. The latter can be explained by the fact that in patients with more severe PAH the pulmonary pressure overrules the gravity effect that is present in normal subjects. The enhancement curve in figure 3 was expressed as per cent increase of the MR signal intensity. For absolute quantification of regional perfusion it is necessary to fit the MRI signal intensity curve to a gamma variate curve [6], taking the enhancement curve of the main pulmonary artery into account. This is required to differentiate between poor perfusion caused by cardiac failure, and poor perfusion caused by increased PVR.

For this reason ceMRI has the potential to quantify the pulmonary perfusion with high temporal and spatial resolution in
$2 \mathrm{D}$ or $3 \mathrm{D}$. In addition, within the same MRI investigation the functional variables of the RV and absolute quantification of global pulmonary flow can be obtained, making it likely that MRI will play an important role in both the diagnosis and monitoring of patients with pulmonary vascular disease in the near future [11, 12].

\section{COMPUTED TOMOGRAPHY}

$\mathrm{CT}$ in its different forms is a noninvasive technique that can quantify the blood flow through the pulmonary vascular bed. The technique is based on the detection of a change in lung density following the passage of contrast. The pulmonary blood flow is expressed per unit volume of lung parenchyma by calculating the percentage of lung parenchyma in a region of interest (ROI), from the relative grey scale or Hounsfield Unit of an ROI, which is composed of air, lung parenchyma and blood, compared with the time density curve in a large blood vessel. The results can also be depicted in a quantitative perfusion map using a colour scale. This method can measure the absolute pulmonary blood flow in $\mathrm{mL} \cdot \mathrm{min}^{-1} \cdot \mathrm{mL}^{-1}$ lung tissue. To exclude the influence of major blood vessels in the lung, the ROI can be chosen in the peripheral parts of the lung. Until now only electron-beam computed tomography (EBCT) has been used to study perfusion of lung tissue (fig. 4) [13-15]. EBCT is a technique that uses an external source of electrons to evoke radiation, enabling a very rapid rotation time and 

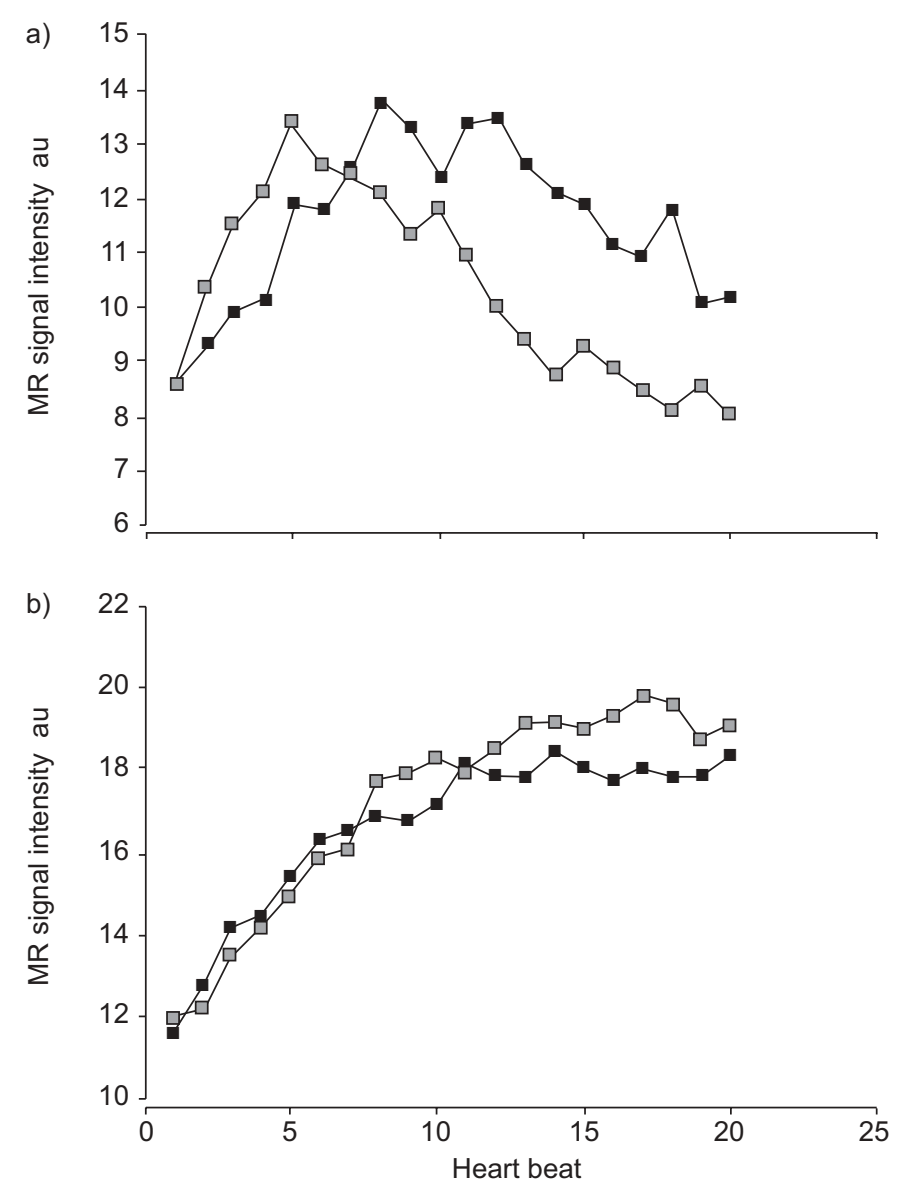

FIGURE 3. a) Perfusion curves in anterior and posterior pulmonary regions, 20 consecutive heartbeats after contrast arrival in the right ventricle (RV), patient with mild pulmonary hypertension (pulmonary arterial pressure (PAP) systolic/diastolic/ mean $(\mathrm{s} / \mathrm{d} / \mathrm{m})=43 / 20 / 31 \mathrm{mmHg})$. The $x$-axis presents heart beat after contrast arrival in the RV. The $y$-axis presents the magnetic resonance (MR) signal intensity in the anterior and posterior region. b) Similar perfusion curves in a patient with moderate pulmonary arterial hypertension (PAP $\mathrm{s} / \mathrm{d} / \mathrm{m}=49 / 31 / 40 \mathrm{mmHg}$ ). anterior; : 1 : posterior.

reducing motion artefacts. However, EBCT is not widely available, especially in Europe. EBCT has been used to study the influence of gravity on the distribution of pulmonary perfusion [16]. Investigators using EBCT found that the density gradient between the dependent and nondependent parts of the lung was reduced in patients with secondary pulmonary hypertension due to systemic sclerosis [17]. JONES et al. [18] have also found an absence in the vertical gradient in perfusion in patients with pulmonary hypertension and a markedly reduced perfusion in pulmonary hypertension when compared with the pulmonary perfusion in healthy subjects. In addition, an increased pulmonary perfusion was measured in patients with pulmonary hypertension, following the administration of adenosine, a vasodilator used in pulmonary reversibility testing at right heart catheterisation. Over the last decade or so the feasibility of using conventional CT systems in perfusion studies has increased with the advent of faster scanners. With the current multidetector row CT (MDCT) with $\geqslant 16$ detectors, volumetric perfusion imaging of section of the
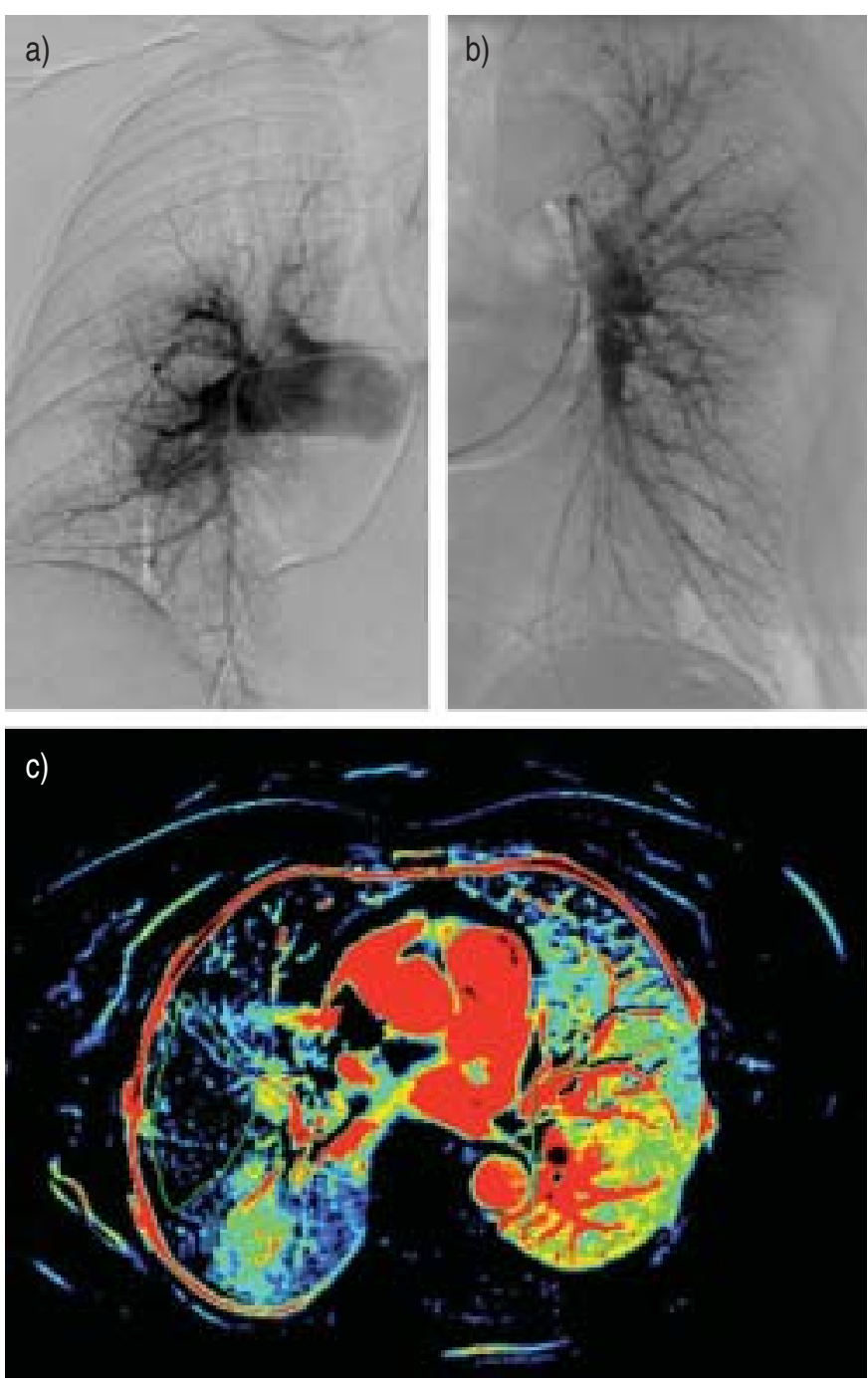

FIGURE 4. Angiographic and perfusion study in a patient with chronic tromboembolic pulmonary hypertension. a, b) Pulmonary angiogram, showing multiple perfusion defects predominantly in the right lung, and c) quantitative map of tissue perfusion at the level of the main pulmonary artery; the colour indicates perfusion rate in $\mathrm{mL} \cdot \mathrm{min}^{-1} \cdot 100 \mathrm{~mL}^{-1}$ tissue. Red is the high end of the scale, blue the low end Note the nearly absent perfusion of the middle lobe, which is compatible with the pulmonary angiogram.

lungs is, in theory, possible. However, CT perfusion research has been restricted to other areas outside the chest $[19,20]$. Figure 4 shows an example of a MDCT perfusion. The perfusion scan was performed in a 70-yr-old female with chronic trombo-embolic pulmonary hypertension, using a four row CT system (SOMATOM Volume Zoom; Siemens, Erlangen, Germany). To make the quantitative map of the lung perfusion the measurements were performed at the level of main pulmonary artery. A dramatic reduction in perfusion of the lung parenchyma can be observed in the middle lobe. The image corresponds well with the pulmonary angiogram, in which the perfusion defects are also clearly visible. MDCT is a promising technique to measure the pulmonary blood flow and is widely available. A disadvantage of both EBCT and MDCT is the high dose of radiation. A major drawback of 
EBCT is that scanners are not available in most centres at this time. Since the evaluation of the lung parenchyma by means of conventional CT is part of the normal work up in dyspnoeic patients, obtaining quantitative information of the pulmonary vascular bed during the same procedure is appealing. However, there is no information available about the value of this technique for the diagnosis or monitoring of pulmonary vascular disease. Furthermore, this technique requires further technical improvement and standardisation to be clinical useful. Finally, the relationship between parenchyma density and pulmonary perfusion should be clarified in order to distinguish primary vascular involvement from loss of alveolar structure.

\section{ELECTRICAL IMPEDANCE TOMOGRAPHY}

The variation of electrical impedance within the thorax is strongly related to cardiac and ventilatory events. Since impedance and blood volume are inversely related, blood volume changes within the lungs can be quantified by measuring the impedance. As the small pulmonary vessels contain the largest pool of blood in the lungs and have the largest distensibility [21, 22], these vessels dominate the pulsatile related volume increase of the pulmonary vascular bed and thus, the impedance change. For this reason the signal might contain significant information about the pulmonary resistance vessels. EIT is a technique that makes it possible to image and quantify impedance changes as a result of differences in the perfusion of the lung. Most studies have been performed using the Sheffield Applied Potential Tomograph Mark I (Sheffield, UK), developed by Barber and Brown in the 1980s, and its successor the Sheffield APT DAS-01P [23]. This system employs eight or 16 electrodes in a ring. A constant current of $\leqslant 5 \mathrm{~mA}$ is applied sequentially to adjacent pairs of electrodes, as indicated in figure 5 . The potential differences between the electrodes are reconstructed into an image of the impedance in the plane spanned by the electrodes. By attaching the electrodes in a circular way around the thorax at the third intercostal space, and using ECG gating, images of the pulmonary perfusion can be obtained [24]. As a consequence of the algorithm used in most of the EIT systems currently available, only differences in impedance are imaged. For the study of pulmonary perfusion related impedance changes, the end diastolic image is chosen as the reference image. At systole, blood is pumped into the pulmonary vascular bed, which leads to an increase in blood volume compared with end diastolic volume, causing a decrease in electrical impedance.

The first clinical studies investigating the possibilities of EIT to detect the pathological changes of the pulmonary vascular bed showed that in emphysematous patients, impedance changes of the pulmonary perfusion are significantly smaller in comparison with healthy subjects, apparently reflecting the reduced pulmonary vascular bed in those patients [24, 25]. Two recent small studies showed that the effects of vasoconstriction and vasodilatation of the small pulmonary blood vessels can be monitored by EIT $[26,27]$. In the first study, the effects of epoprostenol-induced pulmonary vasodilatation on the EIT signal in PAH patients were studied [26]. This study showed that the impedance change was closely related to the decrease of PVR. In the second study pulmonary

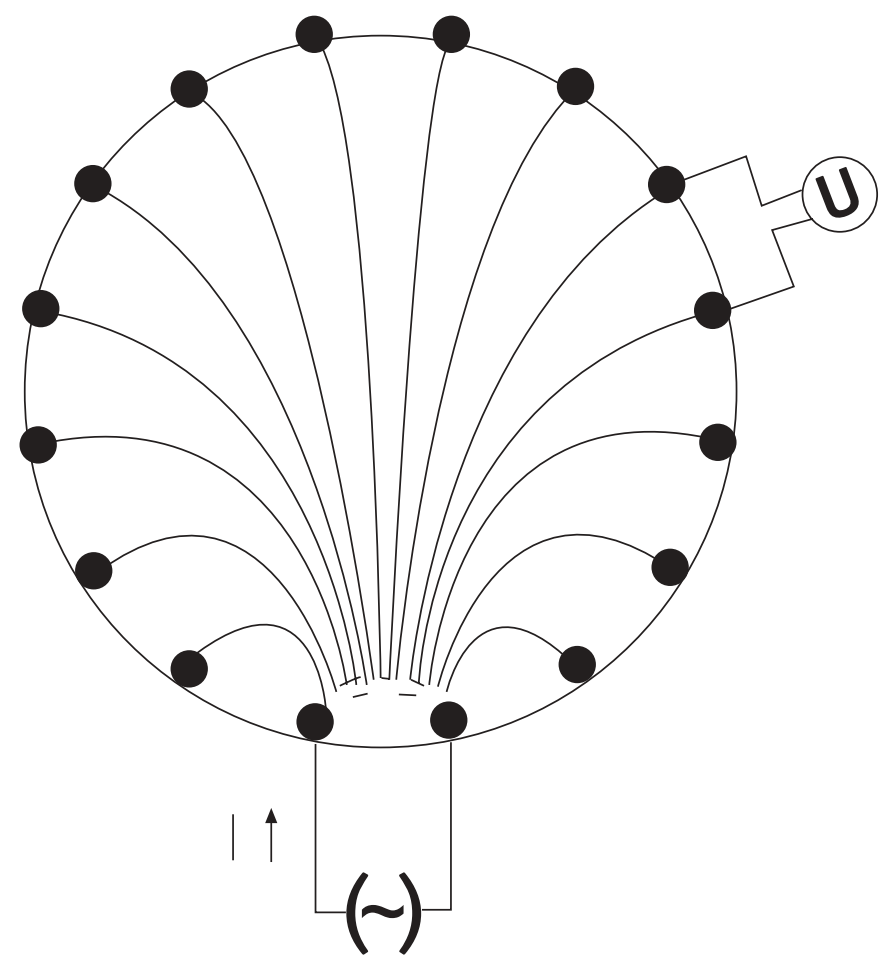

FIGURE 5. Principle of electrical impedance tomography according to the Sheffield method. Current is injected sequentially in adjacent electrode pairs and the potential differences $(U)$ are measured in the remaining electrode pairs. Image reconstruction is conducted along the equipotential lines (shown in figure) with filtered back projection.

vasoconstriction was induced in healthy subjects by inhaling hypoxic air (14\% oxygen), causing a reduction of the EIT signal. Pulmonary vasodilatation was studied in six emphysematous patients with active hypoxic pulmonary vasoconstriction. By inhaling 100\% oxygen, release of hypoxic vasoconstriction could be obtained in the patients. EIT measurements were performed while breathing room air, and during hyperoxia. There was a significant increase in impedance changes with $100 \%$ oxygen, although not in all patients, whereas stroke volume and heart rate remained unchanged [27].

Recent technical advances have led to the prospect of novel EIT machines that are able to reconstruct 3D images of the absolute instead of relative impedance changes during the cardiac cycle $[28,29]$. Although this machine has several theoretical advantages above its predecessors in the determination of the characteristics of the pulmonary vascular bed, clinical data must finally decide whether EIT is a useful tool to monitor pulmonary circulation.

\section{ACETYLENE ABSORPTION}

The most widely used noninvasive parameter of pulmonary vascular function in both health and disease is carbon monoxide transfer factor $(T \mathrm{~L}, \mathrm{CO})[30] . T \mathrm{~L}, \mathrm{CO}$ is traditionally estimated at rest with the single breath method. This technique is firmly established as a valuable routine pulmonary function test. Although it is decreased in pulmonary hypertension, the diagnostic value of the test in pulmonary vascular disease is 
limited [31, 32]. Measuring the absorption of acetylene, a perfusion-limited gas, might be a more accurate indicator for pulmonary vascular function than carbon monoxide, which is a diffusion-limited gas [33]. Currently, two methods are available to measure the absorption of acetylene. The first is the acetylene rebreathing method using breath-by-breath rapid analysis of multiple gases during rebreathing. The slope of the acetylene disappearance curve is used to calculate the pulmonary capillary blood flow, which equals cardiac output in the absence of shunt blood flow. The acetylene rebreathing can be performed either by open circuit rebreathing [34-36] or closed circuit rebreathing [37, 38]. Several studies reported the accurate estimation of cardiac output in healthy subjects and patients with pulmonary hypertension $[39,40]$. This might be of value to monitor patients with pulmonary vascular disease, since stroke volume is a more sensitive measure to monitor treatment effects than PAP [41].

The second technique is the intrabreath method by single exhalation technique developed by NEWTH et al. [42], which can be performed during exercise (fig. 6). If the assumption that acetylene is taken up at a rate proportional to the pulmonary
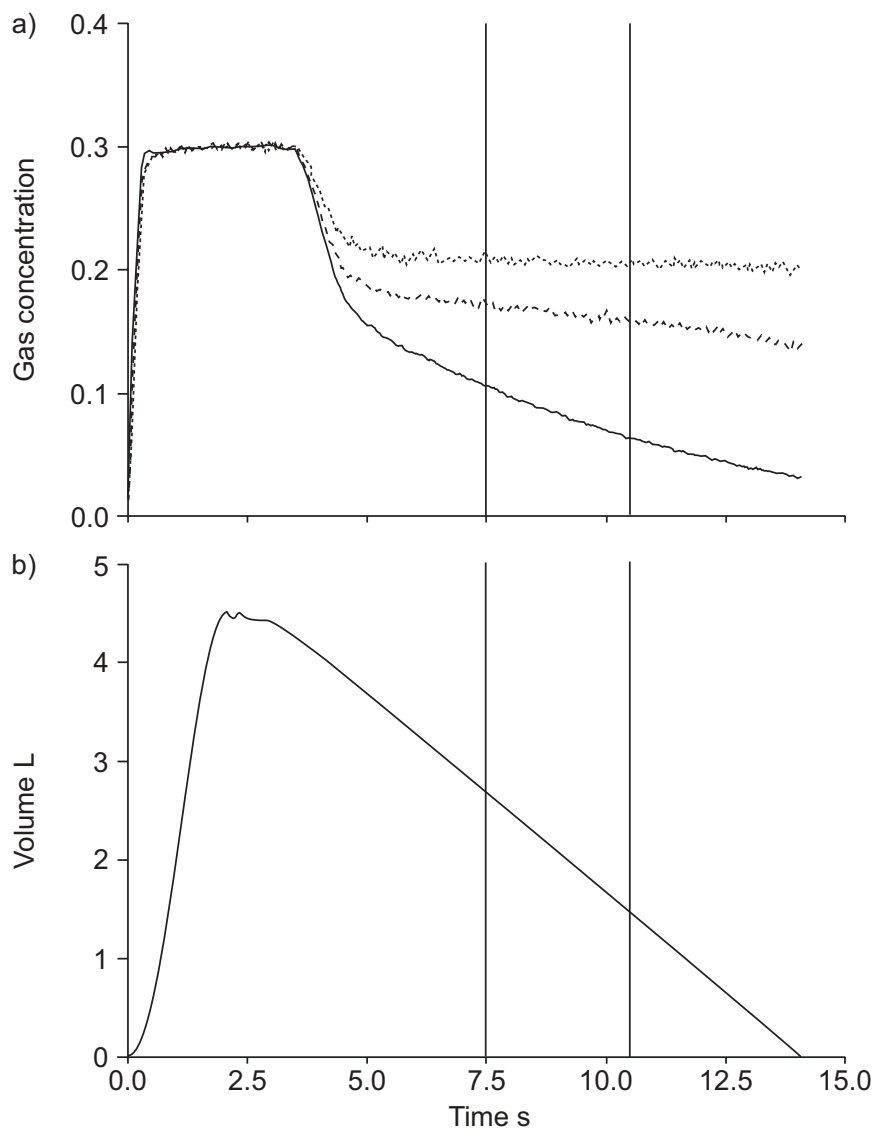

FIGURE 6. Principle of the acetylene single exhalation intrabreath technique, showing inhalation, 3-s breath hold and a constant slow exhalation through a flow restrictor. At constant slow exhalation, the concentration of methane $(\cdots \cdots)$, carbon monoxide (- - ) and acetylene (- - -) are determined by a rapid infrared analyser (a). From the rate of disappearance of acetylene the pulmonary capillary blood flow is calculated. The area between 7.5 and $10.5 \mathrm{~s}$ is the part of the curve used to calculate capillary blood flow (b). capillary blood flow is true, the pulmonary capillary blood flow can be measured from the slope of the acetylene expiration curve [43]. RAMAGE et al. [44] improved this single exhalation technique and showed that by means of rapid analysis of acetylene, methane and carbon monoxide during a single slow exhalation at rest and during exercise, changes in pulmonary blood flow and TL,CO can be accurately measured by means of this single exhalation technique. Further studies in healthy subjects and patients with cardiac disease showed the accuracy of this method [45, 46]. Recently, HUANG et al. [47] provided prediction equations for healthy subjects at rest and during exercise, showing that the acetylene absorption increased during exercise [47]. Whether this increase in acetylene absorption reflects the extent of pulmonary vascular recruitment or an increase in pulmonary blood flow remains unclear [48]. Furthermore, unpublished data from the current authors' laboratory showed that acetylene absorption measured by means of the intrabreath method is abnormally low in patients with $\mathrm{PAH}$, indicating that the theoretical assumptions underlying the test are not fulfilled in these patients. A possible explanation for this finding might be the high flow velocity in the capillaries in PAH in combination with the increased dead space decreasing the absorption rate of acetylene. Although this discrepancy between measured values and reference values might appear to be useful as a diagnostic tool for pulmonary vascular disease, the physiological basis for this discrepancy should first be clarified before the clinical value of the intrabreath method can be assessed.

\section{EXHALED NITRIC OXIDE}

$\mathrm{NO}$ is a molecule with regulatory functions for pulmonary and peripheral blood flow, platelet function, immune reactions and as a neurotransmitter [49]. NO is made by NO synthases, which are present in the respiratory system in epithelial and endothelial cells, and in neural tissue. NO produced by the vascular endothelial cells has an important role in the pulmonary circulation modulating the response to hypoxia [50], increased flow [51] and shear stress [52], by promoting vasodilatation and inhibiting smooth muscle cell growth [53]. Previous work by Giaid and Saleh showed reduced staining of NO synthase in endothelial cells of patients with hypertensive pulmonary vascular disease [54]. In addition, a reduction of the pulmonary vascular bed and thus a reduction of the endothelial cells will cause a reduced production of $\mathrm{NO}$, even if the endothelial cell function is normal.

NO can be measured from exhaled air [55] and is thought to reflect the production of NO from different compartments in the lung, depending on flow rate at exhalation [55]. At slow exhalation, measurement of $\mathrm{NO}$ reflects the production of $\mathrm{NO}$ by the epithelial cells of the airways and this is used to monitor inflammation in asthma [56]. Measurement of NO at a higher flow rate and after wash out of dead space volume is thought to reflect the production of alveolar NO by endothelial cells of the pulmonary vascular bed [55]. Therefore, measurement of exhaled NO at higher flow rates is potentially a method to monitor pathological features of the pulmonary vascular bed.

There are several commercially available automated devices that can measure $\mathrm{NO}$ concentration from a single-breath exhalation after inhalation of $\mathrm{NO}$ free air. $\mathrm{NO}$ is usually expressed in parts per billion and concentration varies with 
flow rate at exhalation [57]. Therefore, flow rate should be recorded during the exhalation and kept at a constant level using flow resistors and at a slightly elevated pressure to minimise contamination from nasal air [58, 59].

Preliminary studies with exhaled NO have shown reduced levels of NO in patients with pulmonary hypertension secondary to systemic disease. CLINI et al. [60] showed a negative correlation between expired NO output and systolic PAP measured by Doppler echocardiography in a group of 34 patients with COPD. Since there was no correlation with any measurement of the lung function and in particular no correlation with carbon monoxide diffusing capacity of the lung the authors concluded that the reduced levels of expired NO were a consequence of impaired endothelial release. In another study, Rolla et al. [61] measured exhaled NO in patients with systemic sclerosis. They found increased NO in patients with systemic sclerosis compared with healthy controls. Dividing the patients into two subgroups, one with pulmonary hypertension (systolic PAP of $>30 \mathrm{mmHg}$ measured by Doppler echocardiography) and one without pulmonary hypertension, showed that patients with pulmonary hypertension produced less NO than patients without pulmonary hypertension. This relationship was also present in the presence of interstitial lung disease.

Release of NO has also been measured in patients with endothelial dysfunction due to primary pulmonary hypertension. CREMONA et al. [62] found a lower exhaled NO in eight patients with primary pulmonary hypertension, in comparison with 20 healthy volunteers. This reduction in exhaled NO was related to reduced pulmonary capillary volume. In contrast with this study, RILEY et al. [63] found no difference between expired NO in primary pulmonary hypertension patients and healthy volunteers, although at exercise NO production increased in the healthy group, whereas it remained stable in the patient group. Finally, FORREST et al. [64] have shown that exhaled NO increased after inhalation of nebulised epoprostenol in patients with pulmonary hypertension due to congenital heart disease, but not in healthy volunteers. Therefore, exhaled NO measurements measured at high flow rate of exhaled air might contain significant information about the pulmonary vascular bed. However, due to conflicting data in the literature, the role of exhaled NO either in the diagnosis or monitoring of pulmonary hypertension remains unclear and should be elucidated in the near future.

\section{CONCLUSION}

Gas exchange in the lungs requires both ventilation and perfusion and these need to be matched. Pulmonary function tests and imaging techniques are currently able to map the function of the ventilatory system in great detail. In contrast, the function of the pulmonary circulation cannot be examined noninvasively in such detail. Even invasive measurements of PVR appear to be unreliable for follow-up in case the pulmonary blood flow has been also changed $[65,66]$. For this reason, the assessment of the exercise capacity using the $6 \mathrm{~min}$ walk test is the most widely used primary end-point in clinical trials in pulmonary hypertension. Although this approach has been successful in the assessment of the effectiveness of therapy for patients in functional class 3 and 4 , this nonspecific parameter cannot be used for the assessment of therapeutic efficacy in earlier stages of pulmonary hypertension. The challenge remains to find a noninvasive technique to diagnose and monitor early stages of pulmonary vascular disease. Therefore, the End Points meeting in pulmonary arterial hypertension published recently [67], recommended the continued development of new technologies to describe pulmonary vascular function.

For clinical purposes any new method should be simple and easy to perform, providing reproducible data. EIT and the intrabreath technique for the measurement of the absorption of acetylene met these criteria. Furthermore, both methods can be used during exercise, which might be of value for the early diagnosis of pulmonary hypertension. Although preliminary data showed that the impedance and acetylene absorption is decreased in pulmonary hypertension, no data exist on the clinical value of the method for the diagnosis of pulmonary hypertension or its value in monitoring the disease. Thus, in parallel with further technical improvements of the methods, the clinical value of these tests in pulmonary vascular diseases should be assessed.

In contrast with EIT and the intrabreath method, CT and MRI measurements provide a more direct quantitative analysis of the pulmonary perfusion. Results of both methods showed that these techniques are able to provide not only structural but also functional information about the pulmonary vascular bed. Further technical improvements of both techniques will be made in the near future, enabling a fast analysis of the pulmonary perfusion. Although there is promising data for both EBCT and MRI, the clinical value of both techniques has not been assessed for the diagnosis of pulmonary disease. Besides, both techniques are technically demanding and expensive, making it unlikely that they will be used routinely in the near future.

In recent years, new insights in the pathobiology of pulmonary arterial hypertension have lead to the development of several effective new treatments for advanced stages of this disease. Although these drugs might change the natural course of the disease, they do not provide a cure. For this reason, there is interest in treatment of the disease earlier in its natural history. Since the evaluation of treatment efficacy during the early stages of pulmonary vascular disease depends critically on accurate and noninvasive tools to diagnose and monitor early pathological changes of the pulmonary circulation, further development and clinical evaluation of the techniques described in large patient populations are warranted.

\section{REFERENCES}

1 Malik AB, Vogel SM, Minshall RD, Tirapputti C. Pulmonary circulation and regulation of fluid balance. In: Murray JF, Nadel JA, Mason RJ, Bouchery HA, eds. Textbook of respiratory medicine. 3rd Edn. Philadelphia, W.B. Saunders Company, 2000; pp. 119-154.

2 Chemla D, Castelain V, Herve P, Lecarpentier Y, Brimioulle S. Haemodynamic evaluation of pulmonary hypertension. Eur Respir J 2002; 20: 1314-1331.

3 D'Alonzo G, Barst R, Ayres S, et al. Survival in patients with primary pulmonary hypertension: results from a 
national prospective registry. Ann Intern Med 1991; 115: 343-349.

4 Sitbon O, Humbert $\mathrm{M}$, Nunes $\mathrm{H}$, et al. Long-term intravenous epoprostenol infusion in primary pulmonary hypertension: prognostic factors and survival. J Am Coll Cardiol 2002; 40: 780-788.

5 McLaughlin V, Shillington A, Rich S. Survival in primary pulmonary hypertension: the impact of epoprostenol therapy. Circulation 2002; 106: 1477-1482.

6 Levin DL, Chen Q, Zhang M, Edelman RR, Hatabu H. Evaluation of regional pulmonary perfusion using ultrafast magnetic resonance imaging. Magn Reson Med 2001; 46: 166-171.

7 Kauczor H-U, Kreitner K-F. Contrast-enhanced MRI of the lung. Eur Radiol 2000; 34: 196-207.

8 Kluge A, Dill T, Ekinci O, et al. Decreased pulmonary perfusion in pulmonary vein stenosis after radiofrequency ablation. Assessment with dynamic magnetic resonance perfusion imaging. Chest 2004; 126: 428-437.

9 Ohno Y, Hatabu H, Murase K, et al. Quantitative assessment of regional pulmonary perfusion in the entire lung using three-dimensional ultrafast dynamic contrastenhanced magnetic resonance imaging: preliminary experience in 40 subjects. J Magn Res Imaging 2004; 20: 353-365.

10 Fink C, Risse F, Buhmann R, et al. Quantitative analysis of pulmonary perfusion using time-resolved parallel 3D MRI - initial results. Rofo 2004; 176: 170-174.

11 Marcus JT, Vonk Noordegraaf A, De Vries PMJM, et al. MRI evaluation of right ventricular pressure overload in chronic obstructive pulmonary disease. JMRI 1998; 8: 999-1005.

12 Roeleveld RJ, Vonk Noordegraaf A, Marcus JT, et al. Effects of epoprostenol on right ventricular hypertrophy and dilatation in pulmonary hypertension. Chest 2004; 125: 572-579.

13 Wolfkiel CJ, Rich SA. Analysis of regional pulmonary enhancement in dogs using ultrafast computed tomography. Invest Radiol 1992; 27: 211-216.

14 Larsen RL, Bridges CR, Beck KC, Hoffman EA. Regional pulmonary blood flow via cine $\mathrm{x}$-ray computed tomography. FASEB J 1990; 4: A1074.

15 Taijk JK, Kugelmass SD, Hoffman EA. An automated method for relating regional pulmonary structure and function: integration of dynamic multislice CT and thin slice high-resolution CT. SPIE Proceedings 1993; 1905: 339-350.

16 Jones AT, Hansell DM, Evans TW. Pulmonary perfusion in supine and prone positions: an electron-beam computed tomography study. J Appl Physiol 2001; 90: 1342-1348.

17 Cailes JB, du Bois RM, Hansell DM. Density gradient of the lung parenchyma at computed tomographic scanning in patients with pulmonary hypertension and systemic sclerosis. Acad Radiol 1996; 3: 724-730.

18 Jones AT, Hansell DM, Evans TW. Quantifying pulmonary perfusion in primary pulmonary hypertension using electron-beam computed tomography. Eur Respir J 2004; 23: 202-207.

19 Miles KA, Griffiths MR. Perfusion CT: a worthwhile enhancement? Br J Radiol 2003; 76: 220-231.
20 Nakashige A, Horiguchi J, Tamura A, Asahara T, Shimamoto F, Ito K. Quantitative measurement of hepatic portal perfusion by multidetector row $\mathrm{CT}$ with compensation for respiratory misregistration. Br J Radiol 2004; 77: 728-734.

21 Enson Y. The normal pulmonary circulation. In: Baum GL, Wolinsky E, eds. Textbook of Pulmonary Diseases. 3rd Edn. Boston/Toronto, Little, Brown and Company; pp. 171-172.

22 Rushmer RF. Properties of the vascular system. In: Cardiovascular dynamics. 3rd Edn. Philadelphia, WB Saunders Company, 1970; pp. 25-32.

23 Barber DC, Brown BH. Applied potential tomography. J Phys E: Sci Instrum 1984; 17: 723-733.

24 Vonk Noordegraaf A, Kunst PW, Janse A, et al. Pulmonary perfusion measured by means of electrical impedance tomography. Physiol Meas 1998; 19: 263-273.

25 Smit HJ, Vonk Noordegraaf A, Marcus T, De Vries PMJM, Postmus PE. Determination of the electrical impedance signal of the pulmonary circulation. Eur J Appl Physiol 2004; 92: $45-49$.

26 Smit HJ, Vonk Noordegraaf A, Roeleveld RJ, et al. Epoprostenol induced pulmonary vasodilatation in patients with pulmonary hypertension measured by electrical impedance tomography. Physiol Meas 2002; 23: 237-243.

27 Smit HJ, Vonk Noordegraaf A, Marcus JT, et al. Pulmonary vascular responses to hypoxia and hyperoxia in healthy volunteers and COPD patients measured by electrical impedance tomography. Chest 2003; 123: 1803-1809.

28 Metherall P, Barber DC, Smallwood RH, Brown BH. Threedimensional electrical impedance tomography. Nature 1996; 380: 509-512.

29 Lionheart WR. EIT reconstruction algorithms: pitfalls, challenges and recent developments. Physiol Meas 2004; 25: 125-142.

30 Roughton FJ, Forester RE. Relative importance of diffusion and chemical reaction rates in determining rate of exchange of gases in the human lung, with special reference to true diffusing capacity of pulmonary membrane and volume of blood in the lung capillaries. J Appl Physiol 1957; 11: 290-302.

31 Mukerjee D, St George D, Knight C, et al. Echocardiography and pulmonary function as screening tests for pulmonary arterial hypertension in systemic sclerosis. Rheumatology 2004; 43: 461-466.

32 Sun XG, Hansen JE, Oudiz RJ, Wasserman K. Pulmonary function in primary pulmonary hypertension. J Am Coll Cardiol 2003; 41: 1028-1035.

33 Grollman A. The solubility of gases in blood and blood fluids. J Biol Chem 1929; 82: 317-325.

34 Stout RL, Wessel HU, Paul MH. Pulmonary blood flow determined by continuous analysis of pulmonary $\mathrm{N}_{2} \mathrm{O}$ exchange. J Appl Physiol 1975; 38: 913-918.

35 Gan K, Nishi I, Chin I, Slutsky AS. On-line determination of pulmonary blood flow using respiratory inert gas analysis. IEEE Trans Biomed Eng 1993; 40: 1250-1259.

36 Nielsen OW, Hansen S, Gronlund J. Precision and accuracy of a noninvasive inert gas washin method for determination of cardiac output in men. J Appl Physiol 1994; 76: 1560-1565. 
37 Sacker MA, Greenletch D, Heiman M, Epstein S, Atkins N. Diffusing capacity, membrane diffusing capacity, capillary blood volume, pulmonary tissue volume and cardiac output by a rebreathing technique. Am Rev Respir Dis 1975; 111: 157-165.

38 Triebwasser JH, Johnson RL, Burpo RP, Campbell WC, Reardon WC, Blomquist CG. Noninvasive determination of cardiac output by a modified acetylene rebreathing procedure utilizing mass sprctrometer measurements. Aviat Space Environ Med 1977; 48: 203-209.

39 Sadeh JS, Miller A, Kukin ML. Noninvasive measurement of cardiac output by an acetylene uptake technique and simultaneous comparison with thermodilution in ICU patients. Chest 1997; 111: 1295-1300.

40 Hoeper MM, Maier R, Tongers J, et al. Determination of cardiac output by the Fick method, thermodilution, and acetylene rebreathing in pulmonary hypertension. Am J Respir Crit Care Med 1999; 160: 535-541.

41 Roeleveld RJ, Vonk Noordegraaf A, Marcus JT, et al. Effects of epoprostenol on right ventricular hypertrophy and dilation in pulmonary hypertension. Chest 2004; 125: 572-579.

42 Newth CJ, Cotton DJ, Nadel JA. Pulmonary diffusing capacity measured at multiple intervals during a single exhalation in man. J Appl Physiol 1977; 43: 617-625.

43 Martonen TB, Wilson AF. Theoretical basis of single breath gas absorption tests. J Math Biology 1982; 14: 203-220.

44 Ramage JE Jr, Coleman RE, MacIntyre NR. Rest and exercise cardiac output and diffusing capacity assessed by a single slow exhalation of methane, acetylene, and carbon monoxide. Chest 1987; 92: 44-50.

45 Zenger MR, Brenner M, Haruno M, Mahon D, Wilson AF. Measurement of cardiac output by automated singlebreath technique, and comparison with thermodilution and Fick methods in patients with cardiac disease. Am J Cardiol 1993; 71: 105-109.

46 Huang YC, Helms MJ, MacIntyre NR. Normal values for single exhalation diffusing capacity and pulmonary capillary blood flow in sitting, supine positions, and during mild exercise. Chest 1994; 105: 501-508.

47 Huang YC, O'Brien SR, MacIntyre NR. Intrabreath diffusing capacity of the lung in healthy individuals at rest and during exercise. Chest 2002; 122: 177-185.

48 Groepenhof H, Lankhaar JW, Boonstra A, Vonk Noordegraaf A. Changes of the recruitment characteristics of the pulmonary vascular bed in pulmonary hypertension. Eur Respir J 2003; 22: Suppl. 45, 146 s.

49 Bhagat K, Vallance P. Nitric oxide 9 years out. J R Soc Med 1996; 89: 667-673.

50 Sprague RS, Thiermermann C, Vane JR. Endogenous endothelium-derived relaxing factor opposes hypoxic pulmonary vasoconstriction and supports blood flow to hypoxic alveoli in anasthetized rabbits. Proc Natl Acad Sci USA 1992; 89: 8711-8715.

51 Cremona G, Higenbottam T, Takao M, Bower EA, Hall LW. Nature and site of action of endogenous nitric oxide in vasculature of isolated pig lungs. J Appl Physiol 1997; 82: 23-31.
52 Hakim TS. Flow-induced release of EDRF in the pulmonary vasculature: site of release and action. Am J Physiol 1994; 267: H363-H369.

53 Giaid A, Saleh D. Reduced expression of endothelial nitric oxide synthase in the lungs of patients with pulmonary hypertension. N Engl J Med 1995; 333: 214-221.

54 Gustafsson LE, Leone A, Persson MG, Wiklund N, Moncada S. Endogenous bitric oxide is present in exhaled air of rabbits, guinea-pigs and humans. Biochem Biophys Res Commun 1991; 181: 852-857.

55 Jorres RA. Modelling the production of nitric oxide within the human airways. Eur Respir J 2000; 16: 555-560.

56 Ashutosh K. Nitric oxide and asthma: a review. Curr Opin Pulm Med 2000; 6: 21-25.

57 Silkoff PE, McClean PA, Slutsky AS, et al. Marked flowdependence of exhaled nitric oxide using a new technique to exclude nasal nitric oxide. Am J Respir Crit Care Med 1997; 155: 260-267.

58 Lunberg JO, Rinder J, Weitzberg E, Lundberg JM, Alving K. Nasally exhaled nitric oxide in humans originates mainly in the paranasal sinuses. Acta Physiol Scand 1994; 152: 431-432.

59 Lundberg JO, Farkas-Szallasi T, Weitzberg E, et al. High nitric oxide production in human paranasal sinuses. Nat Med 1995; 1: 370-373.

60 Clini E, Cremona G, Campana M, et al. Production of endogenous nitric oxide in chronic obstructive pulmonary disease and patients with cor pulmonale. Am J Respir Crit Care Med 2000; 162: 446-450.

61 Rolla G, Colagrande P, Scappaticci E, et al. Exhaled nitric oxide in systemic sclerosis: relationships with lung involvement and pulmonary hypertension. J Rheumatology 2000; 27: 1693-1698.

62 Cremona G, Higenbottam T, Borland C, Mist B. Mixed expired nitric oxide in primary pulmonary hypertension in relation to lung diffusion capacity. Q J Med 1994; 87: 547-551.

63 Riley MS, Pórszász J, Miranda J, Engelen MPKJ, Brundage B, Wasserman K. Exhaled nitric oxide during exercise in primary pulmonary hypertension and pulmonary fibrosis. Chest 1997; 111: 44-50.

64 Forrest IA, Small T, Corris PA. Effect of nebulized epoprostenol (prostacyclin) on exhaled nitric oxide in patients with pulmonary hypertension due to congenital heart disease and in normal controls. Clin Sci (Lond) 1999; 97: 99-102.

65 Castelain V, Chemla D, Humbert M, et al. Pulmonary artery pressure-flow relations after prostacyclin in primary pulmonary hypertension. Am J Respir Crit Care Med 2002; 165: 338-340.

66 Kafi SA, Melot C, Vachiery JL, Brimioulle S, Naeije R. Partitioning of pulmonary vascular resistance in primary pulmonary hypertension. J Am Coll Cardiol 1998; 31: 1372-1376.

67 Peacock A, Naeije R, Galie N, Reeves JT. End points in pulmonary arterial hypertension: the way forward. Eur Respir J 2004; 23: 947-953. 